\title{
INFLUENCE OF AIR TEMPERATURE ON FODDER MOISTURE IN CONSERVATION TECHNOLOGY
}

\author{
Ana Zaica ${ }^{1}$, Radu Ciuperca ${ }^{1}$, Alexandru Zaica ${ }^{1}$, Diana Popa $^{2}$ \\ ${ }^{1}$ National Institute of Research-Development for Machines and Installations \\ Designed to Agriculture and Food Industry, Romania; \\ ${ }^{2}$ Agricultural Research and Development Station Secuieni, Romania \\ zaica_ana@yahoo.com, ciupercaradu@yahoo.com, zaica_alexandru@yahoo.com, \\ dy.hemp420@gmail.com
}

\begin{abstract}
The technology for conservation of hay is a useful method for exploiting the fodder from grasslands and fodder crops, especially from the higher zones of the hilly and mountainous areas. Animal breeders want the grassland areas they exploit to provide the necessary fodder for animals throughout the calendar year. Fodder plants have as essential feature the complete use of the plant mass, which gives a number of advantages, referring first of all to the more efficient use of the environmental conditions, which places them among the most intensive crops. The greatest losses of nutrients are generated when the hay is dried traditionally. These losses reach, in case of adverse weather, even 50-60\%, the drying time increasing to over 6-8 days. This paper addresses some experimental aspects on the way in which the environment influences the drying process of fodder plants, technology based on the conservation, storage and maintenance of the nutritional qualities of the fodder. The results of the experimental researches were realized within a new technology for shortening the period from fodder plants harvesting to obtaining the hay at the storage humidity. When the research was carried out, a pilot ventilation installation with a system for monitoring and controlling the working processes was used. In the research conducted were analysed the parameters of the environment, the parameters of the aeration agent (temperature and humidity), as well as the characteristics of the fodder mass: moisture, temperature, uniformity of drying, and thus information regarding their influence on the drying time was obtained.
\end{abstract}

Keywords: fodder, animals, drying technology, hay.

\section{Introduction}

In modern, sustainable agriculture, livestock breeding occupies an important place, as they provide a large part of human food, but the development of this field of agriculture depends on providing the necessary fodder.

From the grasslands, the fodder is traditionally prepared in the form of hay, and for reducing the loss of nutrients the drying is done on different types of supports: ordinary fences, Swedish fences, pyramids, etc. After drying, the hay is stored in haystacks or hay storehouses; although this way of drying and storing the hay is cheap in terms of investments, it has the following major disadvantages: it requires a high consumption of labour force; nutrient losses are important, especially because of haystack storage [1].

Research in the field of agriculture, as well as agricultural practice show that when applying the procedures for harvesting and preparing fodder plants to obtain hay, the degree of mechanized execution of the necessary works and operations has an essential role.

The main objective within the technology of harvesting, preparation and conservation of fodder plants is to achieve a final product with a nutritional value as close as possible to the initial one of the green fodder, assuming that it fulfils the conditions of a very high quality fodder, both in terms of its botanical composition (a balanced mixture of grasses with perennial legumes) and in those related to the harvesting period [2].

By carrying out the works of suitable quality and with high efficiency we obtain both increased productions of fodder and a hay of superior quality. Higher yields are explained on the one hand by reducing fodder losses at harvest, and on the other by increasing the number of harvesting cycles as a result of reducing the harvesting time (representing the time elapsed from the beginning of fodder plants mowing to the hay storage). The quality of the hay obtained is improved on the one hand, by reducing the period of fodder maintenance on the soil after being mown, and on the other hand, by performing the works at a high-quality level $[3 ; 4]$.

The present study aims at the differences in the traditional drying process of green crops in the field, until they reach a high dry matter content (about $85 \%$ ), which can lead to a level of nutrient loss of about $25 \%$ or even $50 \%$ in unfavorable weather conditions, found in studies in the field. However, 
harvesting pre-dried hay with low dry matter content and drying it with mechanical ventilation systems can reduce losses by up to $15-20 \%$ [4].

The first stage of drying is fast and it involves intense loss of water. At this stage, the stomata remain open and there is a high vapor pressure deficit between forage and air, while water loss may reach $1 \mathrm{~g} /$ hour. In the second phase of drying, after stomata closing, water loss occurs throughout cuticle evaporation $[5 ; 6]$.

Animal breeders in the hilly or mountainous area are particularly interested in the surface of grassland they exploit to provide the necessary feed for the entire calendar year. The problem appears when the altitude increases generating a higher number of days required to keep the animals in the stable during the winter. Thus, at altitudes above $900 \mathrm{~m}$, the stabling period is equal to the grazing period $[4 ; 7]$.

\section{Materials and methods}

The preparation of the hay using the air ventilation method in the process of drying by aeration with the help of the ventilation installation consists in removing water from the fodder in a shorter time, by using the airflows generated by the fan. In this way, the losses of nutrients and vitamins, as well as the losses of mechanical nature are much smaller, and the harvested hay has a green colour, pleasant aroma and a high content of vitamins.

The installation for finalizing hay drying (Fig. 1) is intended to reduce the moisture of the fodder stored in hay storehouses, from 35-40\% to approx. $17 \%$, by ventilation with cold or heated air, for the conservation in optimal conditions for a long time and obtaining qualitative fodder in the last phase of fodder drying technology, Fig. 2.
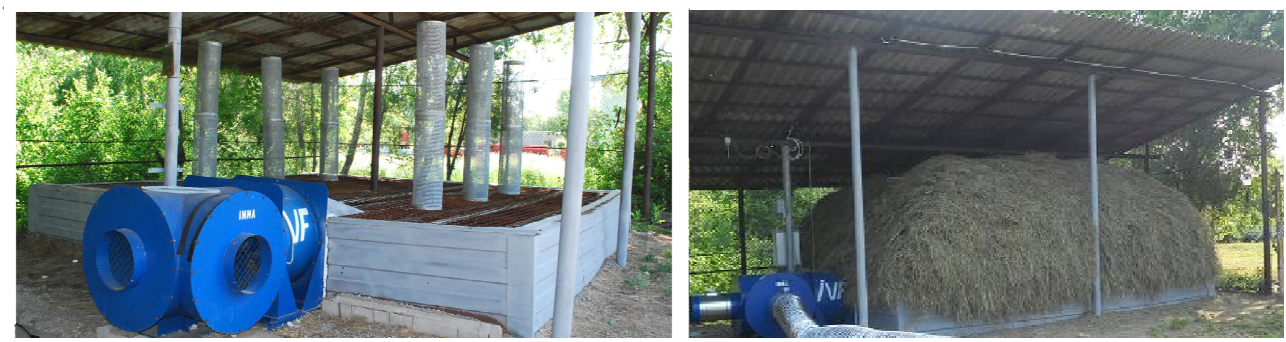

Fig. 1. Experimental model of the installation for fodder ventilation, IVF

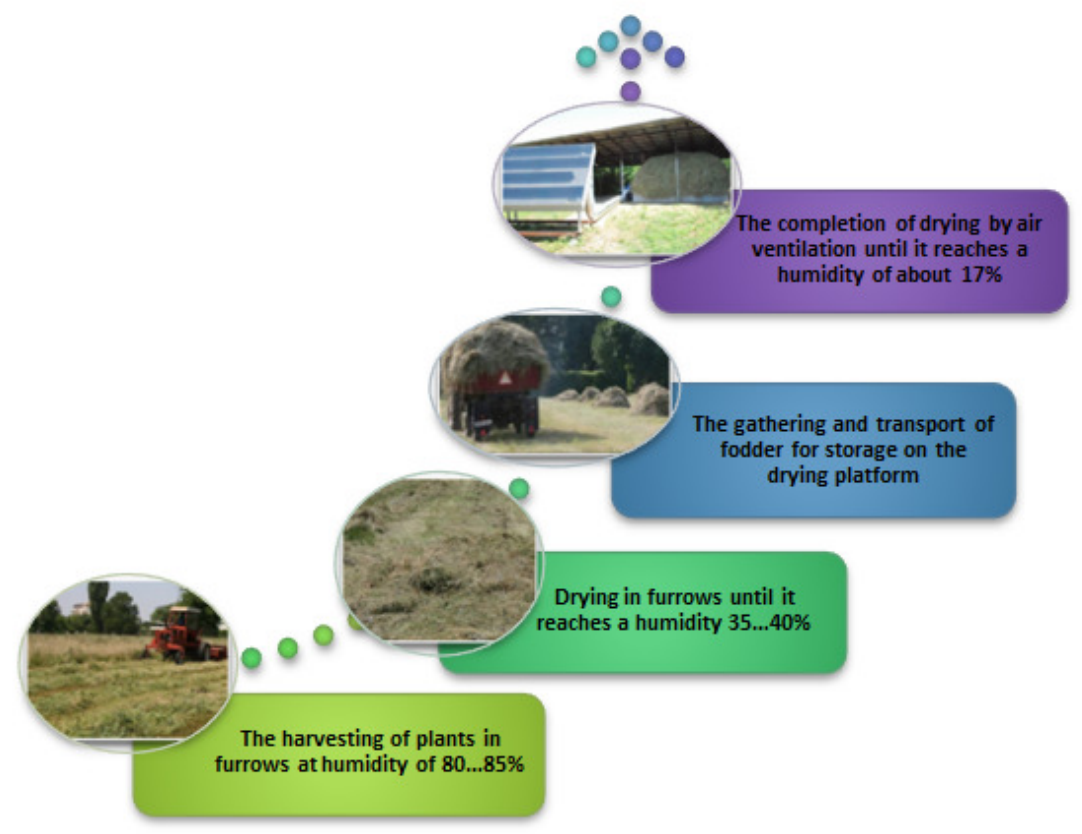

Fig. 2. Phases of the technology for fodder drying by air ventilation 
The factors that influence to a great extent the working process of the aeration equipment, as well as the quantity, the quality of the hay obtained on the grasslands depends on: the production and the initial floral structure of the fodder (at mowing time); the harvesting time (harvesting phenophase); the duration of the hay harvesting and preparation period; the method of harvesting, preparing and preserving the hay; the quality and degree of mechanized execution of the works for harvesting and preparing fodder in the form of hay $[4 ; 8 ; 9]$.

The relative humidity of the air has a considerable influence on the dehydration speed. Increasing the relative humidity of the air reduces its ability to absorb water vapor from the product (hay), slowing evaporation, while a low relative humidity causes a forced elimination of water from the product, with breaks of the plant cell membranes [10].

Upon completion of the aeration drying of the fodder mass stored on special drying platforms, forced cold or hot air circulates. The air is distributed throughout the fodder mass, using fans and channel networks for a uniform distribution, and the drying process begins when the air enters the fodder mass, Fig.1.

In order to optimize the drying process that takes place in fodder aeration (ventilation) installations, it is necessary to approach more deeply the study of the air circulation in the deposited layer. The resistance of the fodder layer to the fan airflow depends on the layer thickness and fodder type. The layer of fodder made from a structure of grass and legume mixtures opposes a greater resistance to the airflow being considered porous medium by its shape, but also by the structure of the component plants.

The parameters that influence the process of fodder drying by aeration with the installation used in the experimental research are the following:

$$
P=f\left(U_{i}, U_{f}, h, \rho, T f, T_{\text {atm }}, U_{\text {aer }}, T_{\text {aer }}, U_{\text {atm }}\right),
$$

where $U_{i}$ - initial moisture of the fodder placed on the drying platform, \%;

$U_{f}$ - final moisture for preserving the hay, less than $18 \%, \%$;

$h$ - maximum height of hay that can be placed on the drying platform, m;

$\rho$ - hay volumetric mass, $\mathrm{kg} \cdot \mathrm{m}^{-3}$;

$T_{f}$ - temperature in fodder mass, ${ }^{\circ} \mathrm{C}$;

$T_{a t m}$ - atmospheric temperature (air as drying agent), ${ }^{\circ} \mathrm{C}$;

$U_{a t m}$ - atmospheric humidity, \%;

$T_{a e r}$ - temperature of the cold/hot air used in the aeration process, ${ }^{\circ} \mathrm{C}$;

$U_{\text {aer }}$ - humidity of the hot/cold air used in the aeration process, $\%$.

As it is found that there are a number of parameters that may have an influence on the aeration process, but not all have the same influence, determinations were made only for some of them during the experiments.

The calculation of the installations for drying by aeration with cold air, for example, is started from the cold air flow required to dry a ton of fodder with the initial moisture of $40 \%$, which has the value of 1100-1300 $\mathrm{m}^{3}$ air $\cdot \mathrm{h}^{-1}$. Depending on the thickness of a fodder layer subjected to drying with a thickness of 2-2.5 m, its density (specific depending on the botanical composition of the fodder, the harvesting cycle, etc.) and the fodder amount to be dried, it is possible to calculate the surface of the dryer and the necessary fans. In order to obtain a maximum quality of the material subjected to drying, it is necessary to know and apply, at any moment, a dependency: Drying agent temperature $=f$ (material moisture), [11].

Depending on the period of plant harvesting and conservation in the form of hay (spring, summer or autumn), as well as on the meteorological conditions specific to the harvesting period (precipitation, temperature and air humidity), the method for drying fodder plants stored on the installation's platform is established, followed by a series of decisive steps, Table 1, during the aeration process and under the conditions imposed by the weather.

When the air temperature is high and the atmospheric humidity index is low, the drying process is finalized by cold air ventilation, because the water content of the plants is lower and the drying process begins as soon as the plants have been mown. When the air temperature is low and the atmospheric humidity is high, the drying process of plants is finalized by ventilation with heated air. 
Steps of aeration drying

\begin{tabular}{|c|c|}
\hline Working step & Methods and activities realized \\
\hline I. Platform loading & Height of fodder layer $2.2 \mathrm{~m}$. \\
\hline \multirow{15}{*}{$\begin{array}{l}\text { II. Drying by } \\
\text { ventilation with cold } \\
\text { air and hot air }\end{array}$} & $\begin{array}{l}\text { Day I - Ventilation with cold air was made for } 8 \mathrm{~h} \text {, manual control from the } \\
\text { control panel; }\end{array}$ \\
\hline & - Pause, switch to the Safety Program. \\
\hline & $\begin{array}{l}\text { Day II }\left(7^{30} \div 15^{30}\right) \text { alternative ventilation with cold air and hot air continued } \\
\text { - Automatic control of cold and hot air ventilation: }\end{array}$ \\
\hline & 1. Ventilation with cold air for $30 \mathrm{~min}$. \\
\hline & 2. Cold air flap is closed and hot air flap is opened. \\
\hline & 3. Ventilation with hot air for $15 \mathrm{~min}$. \\
\hline & 4. Hot air flap is closed and cold air flap is opened. \\
\hline & 5. Ventilation with cold air for $45 \mathrm{~min}$. \\
\hline & $\begin{array}{l}\text { - Ventilation pause for } 1.5 \mathrm{~h} \text {, switch to the Safety Program (set in } \\
\text { Micro PLS): which controls the automatic starting of the fan when the } \\
\text { fodder temperature rises above } 30^{\circ} \mathrm{C} \text {. }\end{array}$ \\
\hline & $\begin{array}{l}\text { The operator follows the values of the parameters on the Micro PLS display: } \\
\text { - air relative humidity, }(\%) \\
\text { - air temperature, }\left({ }^{\circ} \mathrm{C}\right) \\
\text { - temperature in the hay, }\left({ }^{\circ} \mathrm{C}\right)\end{array}$ \\
\hline & $\begin{array}{l}\text { - The ventilation process continues: } \\
\text { - Ventilation with cold air is made for } 30 \text { minutes and then switch to } \\
\text { alternative ventilation: cold air and hot air and continue with alternative } \\
\text { ventilation hot air-cold air; the process is repeated until } 15^{00}\end{array}$ \\
\hline & - Ventilation pause, switch to the Safety Program at $15^{30}$ \\
\hline & $\begin{array}{l}\text { Day III } \\
\text { - Alternative ventilation process, according to the previous day's } \\
\text { schedule. } \\
\text { - Ventilation pause - Safety Program }\end{array}$ \\
\hline & $\begin{array}{l}\text { Day IV } \\
\quad \text { - Ventilation pause - Safety Program }\end{array}$ \\
\hline & $\begin{array}{l}\text { Days V, VI and VII - ventilation with cold air for one hour, followed by } \\
\text { pause with setting on the Safety Program }\end{array}$ \\
\hline \multirow{2}{*}{$\begin{array}{l}\text { III. Monitoring and } \\
\text { control }\end{array}$} & Monitoring and ventilation pause with the Safety Program for 3 days. \\
\hline & $\begin{array}{l}\text { The temperature sensors placed in the hay in the critical areas transmit the } \\
\text { information to the Micro PLS; if the temperature in the hay increases above } \\
\left.\text { the set critical temperature (e.g. } 30^{\circ} \mathrm{C}\right) \text {, the electrical and control system } \\
\text { controls the fan to switch on, and ventilation with cold air is made until the } \\
\text { temperature in the hay falls below the critical temperature. }\end{array}$ \\
\hline IV. Finalisation & $\begin{array}{l}\text { The drying is considered completed when hay moisture is below } 17 \% \text { and } \\
\text { the temperature in the hay is stabilized below } 20^{\circ} \mathrm{C} \text {. }\end{array}$ \\
\hline
\end{tabular}

The operation of completing the drying of fodder plants stored on the platform begins when the aeration system is put into operation and the air sucked by the fan (cold or heated) is introduced through the inlet channel into the uniformization chamber (Fig.1), from where it is distributed in the mass of the stored fodder layer. A layer of material with a height of at least $2 \mathrm{~m}$ is sufficiently thick to prevent the rapid passage of air through the plant mass. At the beginning of the aeration drying process of the first fodder layer, the aeration installation is supplied with cold air and is maintained in working order for 24 hours. If heated air is also used in the drying process, during the drying finalization operation, the preheated air is introduced by the ventilation system in batches of 15-30 min., between the periods of cold air ventilation. In this case fodder drying is made in layers of higher height, the 
first layer representing approx. $40 \%$ of the total amount of fodder that can be stored on the platform. The ventilation program is adapted according to the weather conditions and the parameters of the fodder at the time of storage on the experimental installation platform (temperature, moisture).

\section{Results and discussion}

The experimental model of the installation for fodder ventilation uses both cold and hot air, Fig. 1, and was developed at INMA Bucharest being intended for finalizing drying by cold/hot air ventilation during fodder ventilation process. To heat the air required for ventilation, the installation uses solar radiation, which is converted to heat by means of solar panels and transported through aluminium tubes.

In the experiments, the material used is the grassy fodder plants of natural grasslands. In this case, the fodder necessary to test the installation comes from natural grassland, being a culture used as an experimental lot located at INMA Bucharest. Through these experiments it was sought to determine some of the parameters that influence the drying process by aeration (relation 1). In this sense, determinations and measurements were made, throughout the whole period, following the variation of the following main parameters:

- The temperature and humidity of the atmospheric air, used as an aeration agent in the drying process of fodder;

- The temperature and humidity of the air in the solar panel, part of the installation;

- Temperature and humidity in the mass of the fodder deposited on the installation platform to be dried for optimum storage;

- Duration of the aeration drying process.

During the experimentation period, some particularities were observed, such as: high atmospheric temperatures $\left(T\left({ }^{\circ} \mathrm{C}\right.\right.$ atm. air) and low air humidity $(U(\%)$ atm. air). The material subjected to the aeration process is composed of a mixture of fodder plants harvested from the grassland. The experimental researches for the analysed period had been carried out for 7 days, during 21 effective hours of the aeration drying process of the material deposited on the installation platform, interpreted in graphic form below showing the influence of the temperature and humidity variation of the air used as drying agent, Fig. 3 and Fig. 4.

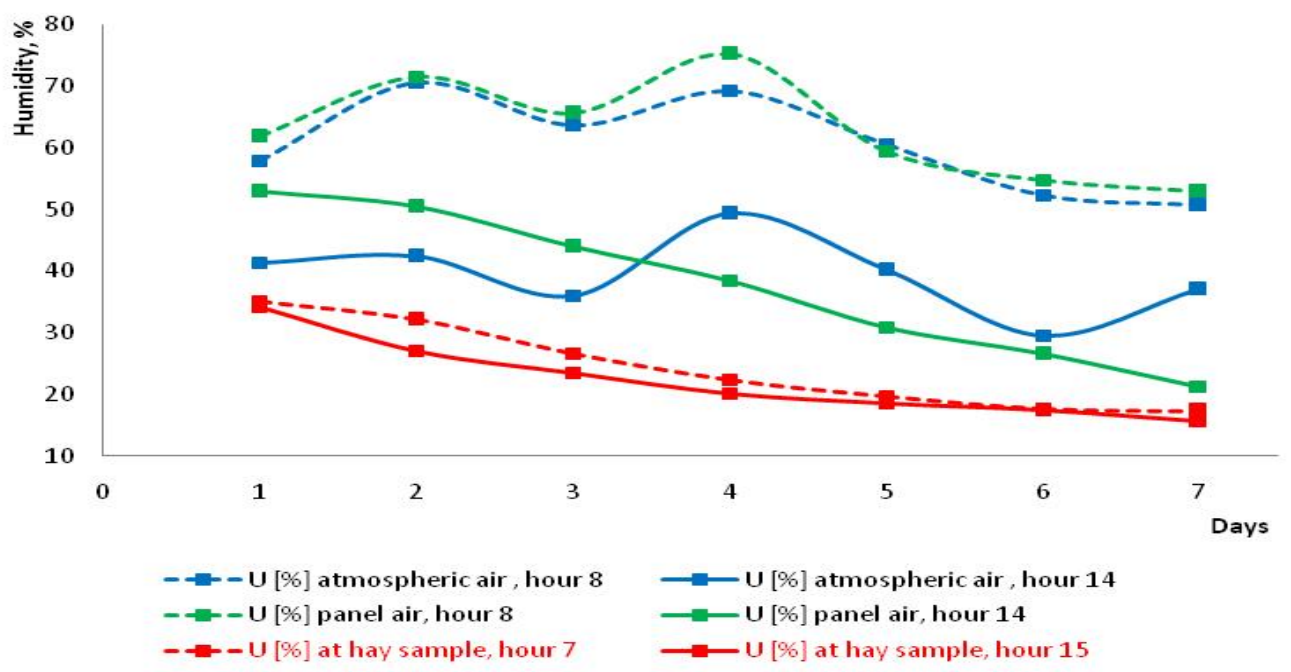

Fig. 3. Moisture variation in fodder mass depending on the drying agent humidity

The atmospheric parameters of the drying agent used in the process directly influence the evolution of the temperature in the fodder mass causing the loss of fodder moisture, Fig. 3.

In Figure 4, the temperature variation in fodder mass is shown. The parameter represents an objective in the optimization of the aeration process, being maintained mainly below the limit of $30^{\circ} \mathrm{C}$. 


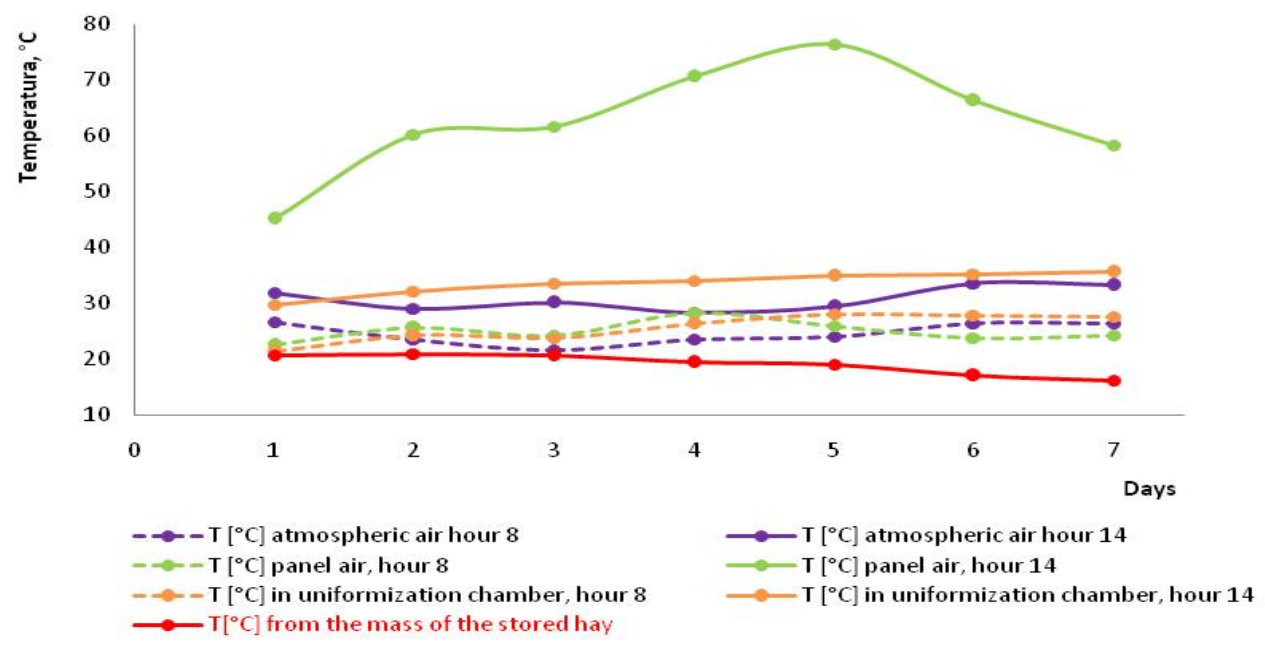

Fig. 4. Moisture variation in fodder mass depending on the drying agent temperature

Analysing the variation of the atmospheric air parameters, as well as of the panel one during the drying process, it is found that the humidity varied between 50-70\% in the first part of the days, while the atmospheric temperature varied between $28-33^{\circ} \mathrm{C}$, reflecting a small influence on the tendency to lose moisture of the material subjected to drying (downward slope of the material moisture loss curve, Fig. 3), observing a constant of approx. $25^{\circ} \mathrm{C}$ of the temperature in the fodder Fig. 4) from day 1 to day 4. In the graph in Fig. 3 the area highlighted in red is the optimal in the drying process, 32-14\% humidity in the 7 days of process.

The favourable weather conditions during the drying phase allowed for the ventilation time to be reduced to only $21 \mathrm{~h}$. The drying uniformity of the fodder on the ventilation platform is high, $97.5 \%$, by using the panel air at $2 \mathrm{PM}$ (approx. $70^{\circ} \mathrm{C}$ ) passing through the sections of the platform (uniformization chamber). The specific drying capacity of the installation was $84.55 \mathrm{~kg}$ per m $\mathrm{m}^{2}$ of the drying platform, the specific electricity consumption per $\mathrm{kg}$ of dry fodder is $0.0276 \mathrm{kWh}$, and $0.103 \mathrm{kWh}$ was consumed to eliminate one $\mathrm{kg}$ of water.

\section{Conclusions}

1. Additional drying of hay with mechanical ventilation systems reduces the loss of nutrients by up to $25-30 \%$ or even $50-70 \%$ in adverse weather conditions. Compared to the drying with cold air, the drying with heated air has the following advantages: it reduces the dependence on the atmospheric conditions during the harvest; it reduces the drying time of fodder; the initial humidity of the fodder subjected to drying can be 10-15\% higher which leads to obtaining higher quality hay.

2. After the experimental research and the previous study, a number of advantages can be drawn from the use of the aeration drying process in the appropriate installations, they are the following: it allows to obtain high quality hay due to the shortened field maintenance of the feed after mowing; dependence on weather conditions during harvest is reduced.

3. Following experimental research in the field of hay production technology, a number of data on the influence of construction elements on the quality of the work process can be found, this article aims to supplement the experimental data and aims to make an important contribution on the interdependence between qualitative, constructive and functional work indices, and the parameters of the aerating agent (humidity and atmospheric temperature) used in the process.

\section{Acknowledgement}

This work was supported by a grant of the Romanian Research and Innovation Ministry, through Programme 1 - Development of the national research-development system, sub-programme 1.2 Institutional performance - Projects for financing excellence in RDI, contract No. 16 PFE. 


\section{References}

[1] Vintu V., Meadows culture and forage crops, Course, Bucharest/Romania, 2004.

[2] Mănişor P., Technologies and equipment for the production and capitalisation of fodder, Bucharest, Romania, 1981.

[3] Cioabla A., Călin L, Irimescu A., Optimization of the drying process of cereals under the conditions of reducing fuel consumption, AGIR Bulletin no. 2-3/2010, April-September, 2010.

[4] Frederiksen H., Dănuţ D., Maşinistru M., Greculescu A., Fodder storage systems - Farm Standards, Manual, Modernization of the Information and Knowledge System in Agriculture Project MAKIS - MADR 04/QCBS/2008 - no. 3166, 2010.

[5] M. A. Neres, D. D. Castagnara, E. E. Mesquita, M. A. Zambom, L. Cristine de Souza, P. S. Rabello de Oliveira, C. C. Jobim, Production of alfalfa hay under different drying methods, Revista Brasileira de Zootecnia, on-line version ISSN 1806-9290, R. Bras. Zootec. vol.39 no.8 Viçosa, Aug. 2010.

[6] J. Isleib, Understanding how hay dries in the field - Having a basic understanding of plant response after mowing can help hay and haylage makers produce higher quality forage, Michigan State University Extension, March 16, 2011.

[7] Samuil C., Production and preservation of fodder, Study Material I.D., Year I, Sem. II,USAMV Iasi, Romanian, 2009.

[8] Hermenean I., Mocanu V., Technologies, machines and installations for harvesting and preservation as hay of the fodder on grasslands, Transilvania University Publishing House, Brasov, 2008.

[9] Wrigley C., 18 - Cereals, Swainson's Handbook of Technical and Quality Management for the Food Manufacturing Sector, Woodhead Publishing Series in Food Science, Technology and Nutrition, 2019, pp. 457-479.

[10] Nedelcu A., Ciupercă R., Popa L., Ştefan V., Dumitraşcu A., Zaica A, Petcu A., Lazăr G., Experimental Research on Process Work of Forage Distributing Machine, International Symposium ISB-INMA TEH Agricultural and Mechanical Engineering, 2015, pp. 673-680.

[11]Zaica A., Nedelcu A., Ciupercă R., Eng. Popa L., Lazăr G, Stefan V., Petcu A., Zaica Al., Research on influence of environmental parameters over the process of drying of volume fodder, International Symposium ISB-INMA TEH Agricultural and Mechanical Engineering, 2015, pp. 723-728. 